\title{
Reversible supranuclear ophthalmoplegia associated with Parkinsonism
}

\author{
R J GUILOFF, R J GEORGE, AND C D MARSDEN \\ From the Department of Neurology, King's College Hospital, London
}

SUMMARY Two patients presented with a supranuclear opthalmoplegia and clinical features otherwise indistinguishable from classical Parkinson's disease. Both had an intercurrent infection, and recovery from the ophthalmoplegia paralleled that from the infection, but the Parkinsonian features improved more gradually on increasing doses of levodopa.

The differential diagnosis between the SteeleRichardson-Olszewski syndrome and Parkinson's disease relies, amongst other points, upon the presence of a supranuclear ophthalmoplegia. ${ }^{12}$ Some believe that the distinction between these two conditions is not so clear and that many patients with Parkinsonism may have limitation of conjugate gaze. ${ }^{3}$ We describe two Parkinsonian patients in whom supranuclear ophthalmoplegia occurred transiently in association with an intercurrent systemic infection.

\section{CASE REPORTS}

Case 1 Male, aged 72 years, with a two-and-a-half year history of micrographia, difficulty crossing roads, unsteadiness, inability to turn in bed or to sit up, and stiffening of the left side of his body. He had experienced several falls and freezing episodes. There was no evidence of previous ingestion of neuroleptic drugs or of encephalitis, and there was no family history of Parkinsonism. He was a heavy smoker with long-standing chronic obstructive airways disease. Recently, he had developed a persistent cough and phlegm and had been feeling unwell.

Examination on 30th October, 1978 showed a lucid man of normal intelligence with mask-like facies, flexed posture and festinant gait. Command movements were slow and reduced to $30 \%$ of normal in upward and downward gaze and on horizontal gaze to the left. Pursuit eye movements were broken

Address for reprint requests: Dr RJ Guiloff, National Hospital for Nervous Diseases, Queen Square, London, W.C.1.

Accepted 13 December 1979 up and similarly reduced in these directions. Doll's eye movements were normal in all directions. Optokinetic nystagmus was absent in the vertical plane. Pupillary reactions were normal. There was akinesia, rigidity and cogwheeling in all limbs, more on the left, but sparing the trunk and neck. There was no tremor. Deep tendon reflexes were brisk, the plantar responses were flexor and sensation was normal. He was apyrexial but had a persistent productive cough, barrel chest, and scattered ronchi in both lungs. A diagnosis of progressive supranuclear palsy was considered. The ESR was 92 $\mathrm{mm} /$ hour, but a full blood count was normal. Chest $\mathrm{x}$-rays showed patchy left lower lobe consolidation. The sputum was heavily infected with pneumococcus. An EEG showed diffuse excess of theta activity. Computerised axial tomography of the brain was normal. On 1st November he was started on trimethoprim $160 \mathrm{mg}$ with sulphamethoxazole 800 $\mathrm{mg}$ twice daily and levodopa $50 \mathrm{mg}$ with carbidopa $5 \mathrm{mg}$ four times a day which was increased subsequently to $100 \mathrm{mg}$ and $10 \mathrm{mg}$ respectively four times a day. There was striking improvement in his eye movements with minimal residual restriction in upward gaze. His Parkinsonism improved later and to a much lesser degree. Repeat chest x-rays and tomograms on 14 November showed resolution of the left lower lobe consolidation.

Case 2 Female, aged 75 years, noticed by her family for three months to have slowing of movements, a shuffling gait, soft speech and tremor of the hands. For a few weeks she had been intermittently confused and forgetful but remained continent and independent in daily living activities. She had been healthy but was on digoxin $0 \cdot 125 \mathrm{mg} /$ day for chronic atrial fibrillation, presumed to be related to ischaemic 
A
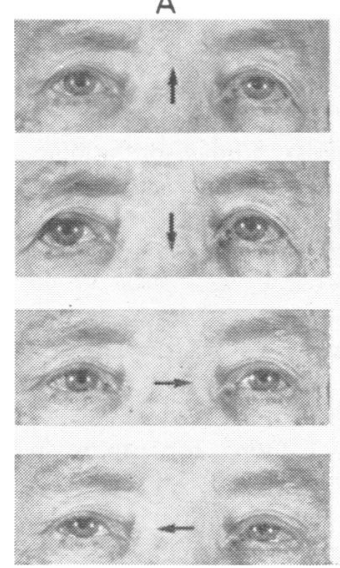

B
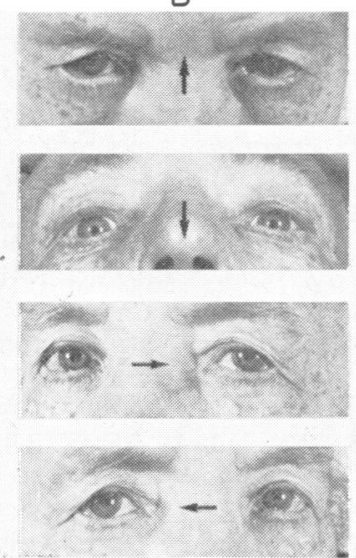

heart disease. Investigations from Outpatients in November, 1978 had shown normal serum thyroxine, haemoglobin, white cell count and chest x-rays. In February, 1979 she developed swelling of the left leg and was admitted to a surgical ward with a diagnosis of deep vein thrombosis. She was given a brief course of warfarin. When seen on 26th February she was pyrexial and dehydrated, with dark and offensive urine and a dry cough. She was mildly confused and had marked motor perseveration, with a masklike facies and a flexed posture; she was unable to stand up or walk. Command and pursuit eye movements were grossly impaired in all directions but Doll's eye movements were normal (fig 1A, B). Optokinetic nystagmus was absent in the vertical plane and markedly reduced in lateral gaze to either side. Convergence was absent, but the pupillary reactions were normal. There was akinesia and rigidity of all limbs, more on the left, and resting tremor of both hands. Deep tendon reflexes were brisk, the plantar responses were flexor and sensation was intact.

A diagnosis of progressive supranuclear palsy was considered. A urinary infection with $\mathrm{E}$. Coli was demonstrated. The white cell count was $11.0 \times 10^{\circ} / 1$, ESR $51 \mathrm{~mm} /$ hour, and haemoglobin $11 \mathrm{~g} / \mathrm{dl}$. Blood urea, electrolytes and blood glucose were normal. Computerised axial tomography of the brain showed mild cerebral atrophy. She was started (on day 1, fig 2) on amoxycillin $250 \mathrm{mg}$ thrice daily, levodopa $50 \mathrm{mg}$ with carbidopa $5 \mathrm{mg}$ twice daily and amantadine $100 \mathrm{mg}$ twice daily. Thirty-six hours afterwards she was no longer pyrexial and her eye movements were normal (fig 1C, fig 2). She was no longer confused. Her Parkinsonism, however, improved gradually up to the 7th day (fig 2). The dose of levodopa was increased to $50 \mathrm{mg}$ four times a day on day 8. Amoxycillin was stopped on day 12. The
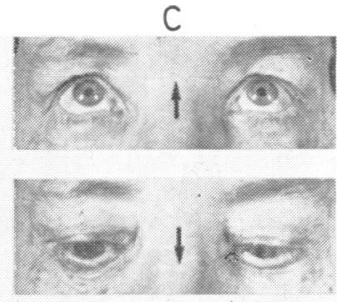

Fig 1 Ocular movements before treatment (temperature $\left.38^{\circ} \mathrm{C}\right) \mathrm{A}$. Command, B. Doll's eye manoeuvre. C. shows eye movements to command 60 hours after treatment started (temperature $36 \cdot 8^{\circ} \mathrm{C}$ ). Arrows indicate direction of eye movement. Case 2 (see text).

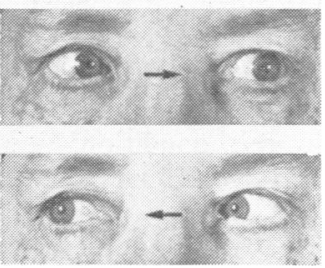

aetiology of her anaemia was not established at this time.

\section{Discussion}

A diagnosis of Steele-Richardson-Olszewski syndrome or progressive supranuclear palsy was considered initially in both patients on the basis of the association of a supranuclear ophthalmoplegia and Parkinsonism. Other features of this syndrome, ${ }^{1}$ such as pseudobulbar palsy, dementia and axial rigidity or nuchal dystonia ${ }^{2}$ were absent. In both
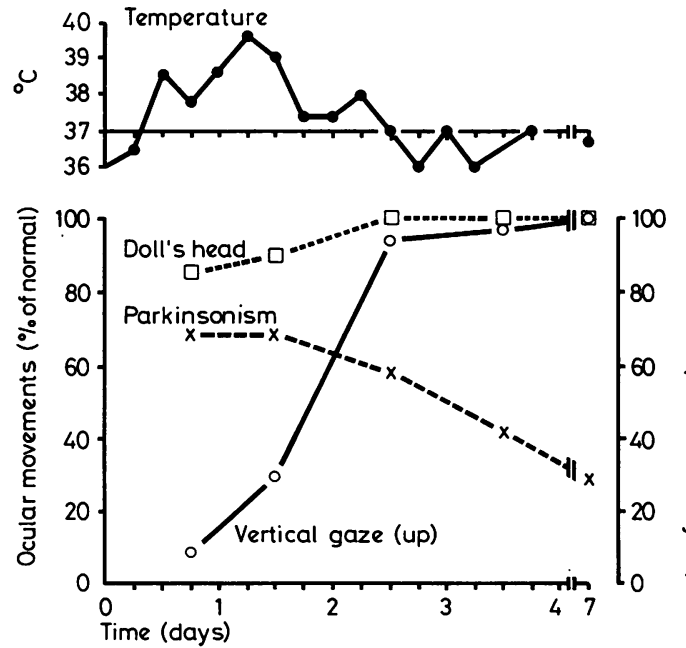

Fig 2 Time course of fever, supranuclear palsy and Parkinsonism in Case 2. Only upward gaze has been plotted but lateral and downward gaze were similarly affected. Disability score range 0-99 (modified King's College Hospital, Parkinson's Disease Rating Scale).$^{16}$ 
patients, the clinical features, other than the opthalmoplegia, and the response to levodopa, were accepted as classical of "idiopathic" Parkinsonism or Parkinson's disease. In both, the ophthalmoplegia disappeared in a few days, after treatment of an associated infection.

In progressive supranuclear palsy, convergence and conjugate ocular movements in the vertical plane are affected first, and lateral gaze palsy develops later and to a lesser degree. ${ }^{18}$ The early and marked involvement of lateral gaze in our patients was atypical for the initial stages of progressive supranuclear palsy. Improvement with levodopa has been described occasionally in this condition ${ }^{4}{ }^{17}$, but most authors have reported no significant change with such treatment. ${ }^{5-11}$.

Corin $e t a l^{3}$ studied the effect of levodopa on oculomotor function in 29 patients with Parkinsonism. Some improvement in both ocular signs and extrapyramidal features was seen in only two patients. In one, improvement was slight for both sets of signs, and in the other it was definite but occurred first for the Parkinsonism and some months later for the ophthalmoplegia. A further patient $^{12}$ had striking improvement in the ophthalmoplegia but his general condition worsened. Corin $e t a l^{3}$ proposed that the oculomotor deficits present in some patients with Parkinsonism and the "generalised abnormalities" were either produced by different mechanisms or had different sensitivity to levodopa. Our own data are more consistent with the first alternative. The time course of recovery from the ophthalmoplegia was quite different from that of Parkinsonism and paralleled more closely recovery from the systemic infection.

It is well known that loss of saccades and pursuit movements with preservation of oculocephalic responses may be a feature of hemisphere disease or upper brain stem lesions or both. ${ }^{15} 18$ The picture has been termed pseudo-ophthalmoplegia or RothBielchowsky syndrome. ${ }^{13}{ }^{14}$ It has been postulated that with upper brain stem lesions the midbrain paramedian reticular formation may be affected bilaterally. ${ }^{15}$

We propose that the supranuclear palsy in our two Parkinsonian patients may have been due, at least partly, to an associated transient encephalopathy produced by a systemic infection. This association may lead to the erroneous diagnosis of progressive supranuclear ophthalmoplegia in patients with Parkinson's disease.

\section{References}

1 Steele JC, Richardson JC, Olszewski J. Progressive supranuclear palsy. Arch Neurol 1964; 10:333-59.

2 Behrmann S, Carroll JD, Janota A, Matthews WB. Progressive supranuclear palsy. Clinico-pathological study of four cases. Brain 1969; 92:663-78.

3 Corin MS, Elizan TS, Bender MB. Oculomotor Function in Patients with Parkinson's Disease. $J$ Neurol Sci 1972; 15:251-65.

4 Mendell JR, Chase TN, Engel WK. Modification by L-Dopa of a case of progressive supranuclear palsy. With evidence of defective cerebral dopamine metabolism. Lancet 1970; 1:593-4.

5 Wagshul A, Daroff RB. L-Dopa for progressive supranuclear palsy. Lancet 1969; 2:105-6.

6 Gilbert JJ, Feldman RG. L-Dopa for progressive supranuclear palsy. Lancet 1969; 2:404.

7 Sacks OW. L-Dopa for progressive supranuclear palsy. Lancet 1969; 2:591-2.

8 Jenkins R. L-Dopa for progressive supranuclear palsy. Lancet 1969; 2:742.

9 Gross M. L-Dopa for progressive supranuclear palsy. Lancet 1969; 2:1359-60.

10 De Renzi E, Vignolo LA. L-Dopa for progressive supranuclear palsy. Lancet 1969; 2:1360.

11 Klawans HL. L-Dopa for progressive supranuclear palsy. Lancet 1969; 2:1359.

12 Corin MS, Mones RJ, Elizan TS, Bender MB. Paresis of Vertical Gaze in Basal Ganglia Disease. J Mount Sinai Hosp 1972; 39:330-42.

13 Cogan DG. Neurology of the Ocular Muscles 2nd ed. Springfield: CP Thomas, 1956.

14 Kestembaum A. Clinical Methods of Neuro-Ophthalmologic Examination 2nd ed. New York: Grune and Stratton, 1961.

15 Daroff RB, Hoyt WF. Supranuclear Disorders of Ocular Control Systems in Man. Clinical Anatomical and Physiological Correlations-1969. In: Bach-yRita P, Collins CC, eds. The Control of Eye Movements. New York: Academic Press, 1971:175-235.

16 Marsden CD, Parkes JD, Rees JE. A year's comparison of treatment of patients with Parkinson's Disease with levodopa combined with carbidopa versus treatment with levodopa alone. Lancet 1973; 2:1459-62.

17 Dehaene I, Bogaerts M. L-Dopa in progressive supranuclear palsy. Lancet 1970; 2:470.

18 Dix MR, Harrison MJG, Lewis PD. Progressive Supranuclear Palsy (The Steele-RichardsonOlszewski Syndrome). A report of nine cases with particular reference to the mechanism of the oculomo tor disorder. J Neurol Sci 1971; 13:237-56 